\title{
WildFire Smoke Exposure Worsens Learning Outcomes
}

Preprint, compiled February 14, 2022

\author{
Jeff Wen (D) ${ }^{1 \dagger}$ and Marshall Burke (D) $1,2,3, \diamond$
}

${ }^{1}$ Department of Earth System Science, Stanford University, Stanford, CA 94305

${ }^{2}$ Center on Food Security and the Environment, Stanford University, Stanford, CA 94305

${ }^{3}$ National Bureau of Economic Research, Cambridge, MA 02138

$\dagger$ E-mail (corresponding author): jlwen@ stanford.edu; Twitter: @ jeffliwen

${ }^{\diamond}$ E-mail: mburke@stanford.edu; Twitter: @MarshallBBurke

The paper is a non-peer reviewed preprint submitted to EarthArXiv. It has been submitted for publication in a peer reviewed journal, but has yet to be formally accepted for publication.

\begin{abstract}
Wildfires have increased in frequency and severity over the past two decades, threatening to undo substantial air quality improvements. We investigate the effect of wildfire smoke exposure on learning outcomes across the US using standardized test scores from 2009-2016 for nearly 11,700 school districts and satellite-derived estimates of daily smoke exposure. Relative to a school year with no smoke, average cumulative smoke-attributable $\mathrm{PM}_{2.5}$ exposure during the school year $\left(\sim 35 \mu \mathrm{g} / \mathrm{m}^{3}\right)$ reduces test scores by $\sim 0.15 \%$ of a standard deviation. These impacts are more pronounced among younger students and are observed across differing levels of economic disadvantage and racial-ethnic composition. Additionally, we project that smoke $\mathrm{PM}_{2.5}$ exposure in 2016 reduced discounted future earnings by nearly $\$ 1.7$ billion ( $\$ 111$ per student). Roughly $80 \%$ of these costs are borne by disadvantaged districts. Our findings quantify a previously unaccounted for social cost of wildfire that is likely to worsen under a warming climate.
\end{abstract}


$\Upsilon^{2}$ HE frequency and severity of wildfires throughout the Western United States have increased in recent decades and are expected to worsen as the climate continues to warm [1]. Literature has linked these wildfire events and the smoke they generate to a variety of social and economic impacts, in particular health and infrastructure related damages $[2,3,4]$. Yet emerging evidence from studies on non-wildfire air pollutants suggests that wildfire smoke exposure could have much wider-ranging impacts, including possible negative effects on human cognition $[5,6,7,8,9,10,11,12,13,14,15,16,17,18,19,20]$. Such effects would have broader implications for human capital formation and longer-term economic well-being, as well as for the social costs of a warming climate, but have not been documented in existing literature.

Recent studies have focused on the biological channels through which air pollution exposure might affect human health and have found that non-wildfire-related air pollution exposure is associated with higher likelihood of neuroinflammation $[5,6]$, and document significant associations between $\mathrm{PM}_{2.5}$ exposure and increased risks for Alzheimer's, dementia, and Parkinson's disease [21,22]. Epidemiological and social science studies have begun to draw links between air pollution exposure and cognitive performance on real-world tasks, including declining performance in chess tournaments [8], stock trading [9], call center productivity [10], umpire decisions [11], cognitive assessments [15, 17, 18, 19, 23], and online brain games [12] Similar to our setting, a handful of studies have assessed how student test scores have responded to variation in exposure to ambient (non-wildfire) air pollution [13, 16, 20, 7, 24]. A recent study investigates the association between long-term ambient air pollution exposure and student test performance in the US and find negative impacts of increased ambient air pollution [24] Other studies have used research designs that more plausibly isolate variation in pollution from other factors that might also affect student test performance. These studies have found that short-term changes in air pollution on the day of the exam led to declines in student performance [13, 16, 20, 7] and decreased future earnings [13] and that installation of air filters in schools in the vicinity of a gas leak improved student Math and English test scores even into the following year [25]. While these studies focus on the impact of air pollution on student test performance, to our knowledge there are no studies that focus on wildfire smoke particulate matter, which recent studies suggest could potentially be more harmful to human health than other sources of particulate matter [26, 27] and is likely the fastest growing source of air pollution in the US [28].

As wildfire activity has dramatically increased in recent decades due to a rapidly warming climate and a century of fire suppression practices across the Western United States, wildfire smoke has become an increasingly important contributor to surface particulate matter $<2.5 \mu \mathrm{g} / \mathrm{m}^{3}\left(\mathrm{PM}_{2.5}\right)$ concentrations [28]. Increasing wildfire-derived $\mathrm{PM}_{2.5}$ threatens to undermine decades of progress in improving overall $\mathrm{PM}_{2.5}$ concentrations - improvements brought about by changes in manufacturing practices, energy production, and legislation [29, 30, 28, 31]. Furthermore, while exposure to ambient smoke-derived $\mathrm{PM}_{2.5}$ appears more evenly distributed across economic and racialethnic groups than other sources of $\mathrm{PM}_{2.5}$ [28], even similar ambient exposures may differentially impact communities due to a variety of factors including differences in housing or school char- acteristics [32, 33] or differences in knowledge of or ability to undertake protective behaviors. Ultimately, the differences in realized exposures could result in differential impacts across racialethnic and socioeconomic groups, as has now been documented for other environmental exposures [34, 35, 36, 37, 38, 39].

Here we quantify the impact of wildfire smoke exposure on learning outcomes across the US, as measured by standardized test scores, and estimate potential heterogeneous impacts of this exposure across demographic and socioeconomic groups. We first develop estimates of local-level wildfire-smoke-attributable $\mathrm{PM}_{2.5}$ exposures across the US and over time, using a combination of high resolution predicted $\mathrm{PM}_{2.5}$ data and satellite derived wildfire smoke plumes [40, 41] (Methods). We then study the effect of cumulative smoke exposure during the school year on student learning outcomes, as measured through harmonized national test score data for students from 3rd-8th grades collected across nearly $\sim 11,700$ school districts between 2009-2016. These comprehensive longitudinal data allow us to plausibly isolate the effect of wildfire-smoke-attributable $\mathrm{PM}_{2.5}$ on student learning outcomes.

We model the effect of smoke exposure on student test performance using fixed-effects regression models that account for unobserved time-invariant differences in smoke exposure and test scores across districts as well as time-trending year-grade specific differences common to all locations (Methods). As there has been an upward trend in both wildfire smoke exposure and test performance across our study period as well as large regional differences in average smoke exposure (Figure 1), simple cross sectional or time series regressions could conflate overall trends or average differences in smoke with other factors that affect learning outcomes. Rather than comparing across districts, our approach compares particular districts to themselves over time as smoke exposure fluctuates, after accounting for any differences in grade-specific national averages between years. We incorporate gridded temperature and precipitation data [42] to flexibly control for temperature and precipitation-related impacts on student performance, especially as temperature has been shown to affect learning and may be correlated with wildfire activity $[34,35]$.

We then examine the heterogeneous impacts of wildfire smoke exposure by estimating whether responses differ between school and non-school days or by student age groups, levels of economic disadvantage, and/or race and ethnicity - dimensions along which earlier research has suggested environmental exposures and impacts might differ. Finally, to quantify the economic magnitude of smoke-related impacts, we explore how learning outcomes differ between a less severe compared to a more severe smoke year and provide estimates of the impact of wildfire-smoke-attributable $\mathrm{PM}_{2.5}$ in terms of students' lost future earnings, using literature-derived estimates of the relationship between test scores and earnings (Methods).

\section{RESULTS}

We find that smoke exposure in the year leading up to the test has a statistically significant negative impact on learning outcomes (Figure 2). An additional $\mu \mathrm{g} / \mathrm{m}^{3}$ of cumulative smoke $\mathrm{PM}_{2.5}$ in the year leading up to the exam decreases average test scores by $0.003 \%$ (95\% confidence interval (CI): $-0.005 \%$ to 

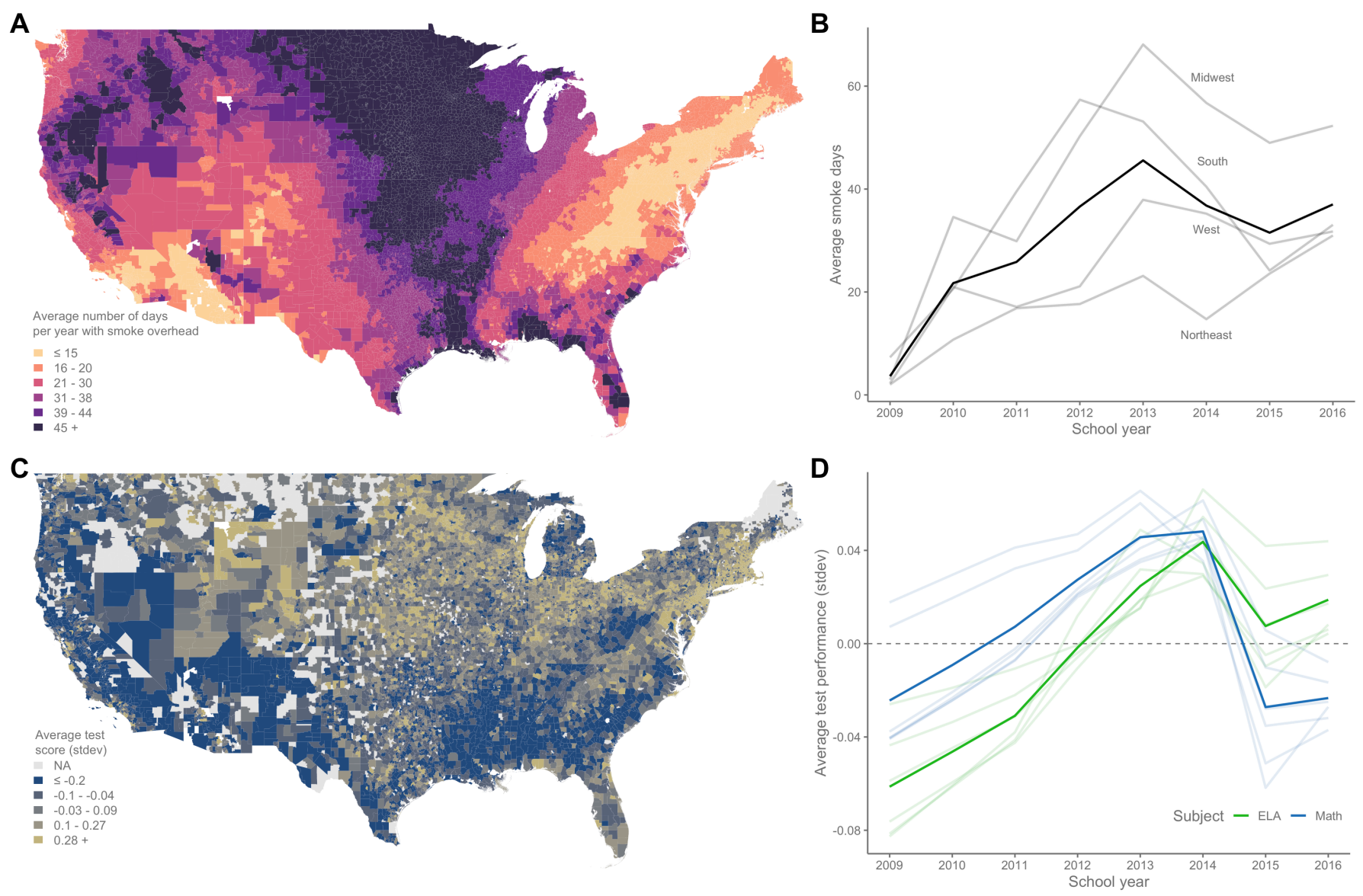

Figure 1: Spatiotemporal variation in wildfire smoke exposure and average test scores. A. Spatial distribution of the average number of days with smoke overhead from 2009-2016 for each school district in the continental US. B. Temporal variation in the average number of smoke days for various census regions. Black line represents the average over the entire US C. Spatial distribution of test scores. Math and ELA scores are averaged across the study period from 2009-2016 for each district and are represented in standard deviations. D. Average test performance relative to the national reference cohort. Each state's standardized test results are scaled to the nationally comparable (National Assessment of Educational Progress) test. Faded lines represent grade specific performance and darker lines represent the average over all grades.

$-0.001 \%)$. The effect is similar across subjects with decreases in English language arts (ELA) test score by $0.003 \%(95 \%$ CI: $-0.005 \%$ to $-0.002 \%$ ) and math test scores by $0.002 \%$ (95\% CI: $-0.004 \%$ to $-0.001 \%$ ) of a standard deviation for school districts across the US from 2009-2016 (Figure 2B). These results are robust to flexible functional forms such as higherorder polynomials of the smoke $\mathrm{PM}_{2.5}$ response relationship and are fairly linear (Figure 2A).

Comparing school day vs. non-school day exposure, we find that smoke exposure on school days has a statistically significant negative effect on test performance where an additional $\mu \mathrm{g} / \mathrm{m}^{3}$ of cumulative smoke $\mathrm{PM}_{2.5}$ on school days decreases average test scores by $0.004 \%$ (95\% CI: $-0.008 \%$ to $-0.001 \%$ ) of a standard deviation. Exposure on non-school days results in a smaller negative effect that is also statistically significant (compared to no effect). Point estimates suggest the effect of exposure on a school day is nearly twice as harmful as exposure on a nonschool day for both ELA and math, although these estimates are not statistically distinguishable from one another (Wald test for equivalence of coefficients: $\mathrm{F}_{1,5092}=0.614, \mathrm{P}=0.433$ ).

On school days with smoke in the air, the average ambient smoke-attributable $\mathrm{PM}_{2.5}$ concentration is $6 \mu \mathrm{g} / \mathrm{m}^{3}$. Given these averages, we estimate that exposure to an additional school week (five school days) of smoke in the year prior to the exam lowered scores by $0.131 \%$ (95\% CI: $-0.245 \%$ to $-0.017 \%$ ) of a standard deviation. We focus on cumulative smoke $\mathrm{PM}_{2.5}$ exposure on school days in the year prior to the exam for the remainder of the analysis because our measurement of exposure is at school locations and exposure on non-school days is uncertain.

While our main analysis clusters standard errors at the county level to account for correlation in errors across districts within the same county, we conduct additional analysis using a randomization inference approach to test the sharp null hypothesis of no effect for additional smoke $\mathrm{PM}_{2.5}$ exposure on school days by randomly permuting test scores across districts within a county. This approach non-parametrically estimates statistical significance and is especially beneficial in the presence of fuzzy clustering where smoke exposure may be correlated within the cluster, but the correlation is imperfect [43, 44]. We find that the estimated effect of school day smoke $\mathrm{PM}_{2.5}$ exposure is significantly different from the distribution of permuted effect estimates (Figure 2C). 

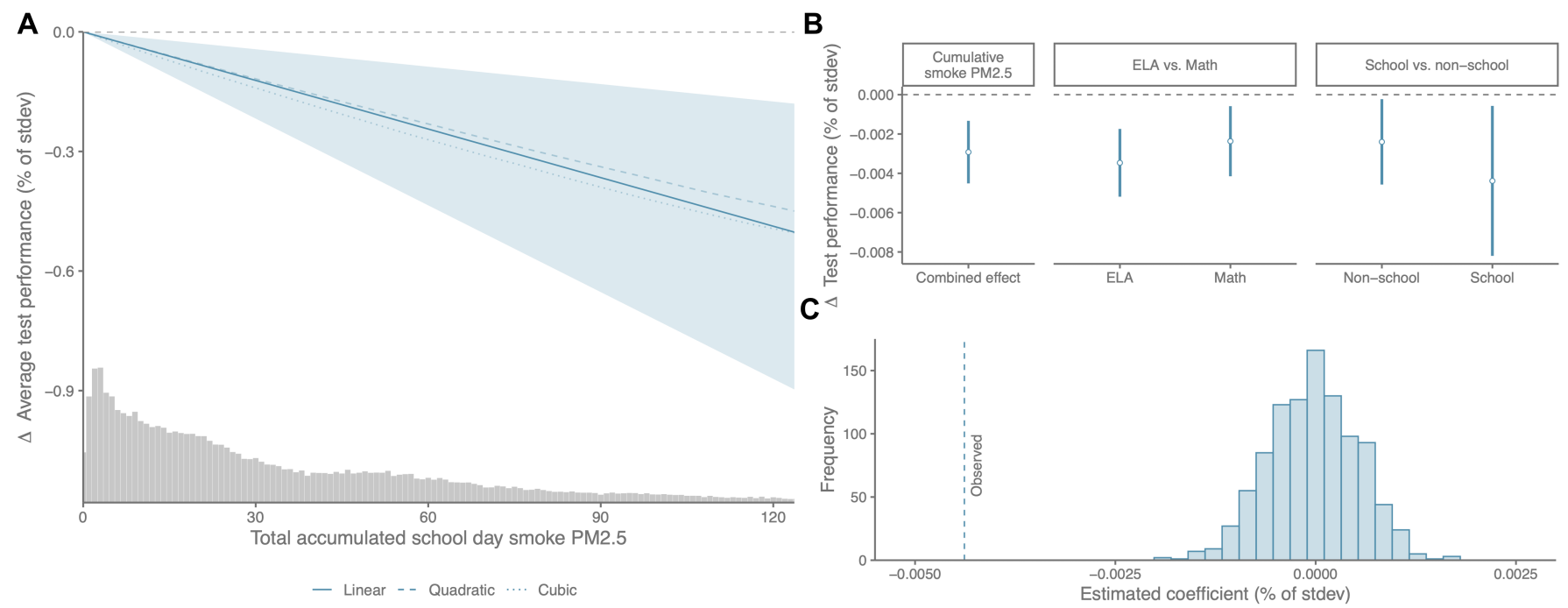

Figure 2: Effect of wildfire smoke exposure on student test scores. A. Test performance declines as a function of total accumulated daily smoke $\mathrm{PM}_{2.5}$ during the school year prior to the test (only on school days).; shaded area shows bootstrapped $95 \%$ confidence intervals. $\Delta$ Test performance is the change in test score relative to the national NAEP reference cohort, measured in percent of a standard deviation. B. Effect estimates of an additional $\mu \mathrm{g} / \mathrm{m}^{3}$ of smoke $\mathrm{PM}_{2.5}$ in the year prior to the exam for school versus non-school day exposure, the combined average effect, and English language arts (ELA) and Math. C. Randomization inference test (1000 permutations) showing the estimated effect size of an additional $\mu \mathrm{g} / \mathrm{m}^{3}$ of smoke $\mathrm{PM}_{2.5}$ on school days when outcomes are randomly permuted across districts within each county. The observed effects are significantly different from the randomization test effects.

Although we do not have access to evacuation orders related to each fire, we test whether the identified effects are driven by smoke $\mathrm{PM}_{2.5}$ exposure or by direct wildfire effects by using a similar empirical strategy as before but drop districts that are certain distances from the nearest fire perimeter provided by the National Interagency Fire Center (NIFC) in that year (Methods). We find that the identified effect estimates remain fairly stable up to 6.2-miles (10-kilometers), which provides evidence that the effects identified are likely not driven by direct wildfire effects but rather by the smoke $\mathrm{PM}_{2.5}$ impacts aligning with the research motivation of this paper (Supplemental Figure 3). We also test whether the effects of smoke exposure during previous school years carry over into test performance in the current year. While results are somewhat noisy, point estimates suggest that learning impacts can persist into future years (Supplemental Table 4).

We find strong evidence of heterogeneous effects of smoke $\mathrm{PM}_{2.5}$ among sub-populations. In line with previous studies that find negative effects of air pollution exposure on younger children $[45,7,46]$, we find that additional smoke $\mathrm{PM}_{2.5}$ on school days is statistically significant and negative for primary school (3rd-5th grades) but does not appear to affect secondary school students (6th-8th grade) (Figure 3). Among primary school children, each additional $\mu \mathrm{g} / \mathrm{m}^{3}$ of cumulative smoke $\mathrm{PM}_{2.5}$ on school days decreases scores by $0.012 \%$ (95\% CI: $-0.019 \%$ to $-0.005 \%$ ) of a standard deviation.

Consistent with previous work [28, 47], we find that exposure to ambient $\mathrm{PM}_{2.5}$ from wildfire smoke is largely similar across racial-ethnic subgroups (Supplemental Table 1) and across different levels of economic disadvantage (Supplemental Table 2). However, similar ambient exposures could result in very different impacts across subgroups, due to potential differences in how pollutants infiltrate into indoor environments and/or differences in how a given increase in wildfire smoke exposure interacts with baseline differences in other pollutant exposures or other determinants of learning outcomes. We thus consider the differential responses to a given exposure across districts with varying levels of economic disadvantage and proportions of nonWhite students. Each district's level of economic disadvantage is measured by the Federal EdFacts data system and is typically defined at the state level as the proportion of students eligible for free or reduced-price lunch [48]. The proportion of non-White students in a district is calculated by subtracting the proportion of White students from 1 . The proportion of White students is collected by the Common Core of Data and aggregated by the SEDA team to the district level [49]. We determine if districts have "High" versus "Low" levels of economic disadvantage and proportion of non-White students by thresholding at the median value of each variable. We emphasize that the estimated moderating effect of economic disadvantage or racial-ethnic categories in this analysis should be understood to reflect the possible effect of racist and/or discriminatory policies or attitudes on outcomes, rather than as reflecting inherent characteristics of individuals or communities that fall into these categories.

We find that districts with high economic disadvantage and high proportion of non-White student population as well as districts with low economic disadvantage and low proportion of non-White student population are more negatively affected by smoke $\mathrm{PM}_{2.5}$ exposure compared to other subgroups (Figure 3). For students in districts with high economic disadvantage and a high proportion of non-White students, each additional $\mu \mathrm{g} / \mathrm{m}^{3}$ of cumulative smoke $\mathrm{PM}_{2.5}$ on school days lowered test scores by $0.008 \%$ (95\% CI: $-0.014 \%$ to $-0.003 \%$ ) of a standard deviation. Districts with low economic disadvantage and low proportion of non-White students also appeared negatively impacted by additional smoke $\mathrm{PM}_{2.5}$ with decreases of $0.006 \%$ (95\% CI: $0.012 \%$ to $-0.001 \%$ ) of a standard deviation. When we separate 


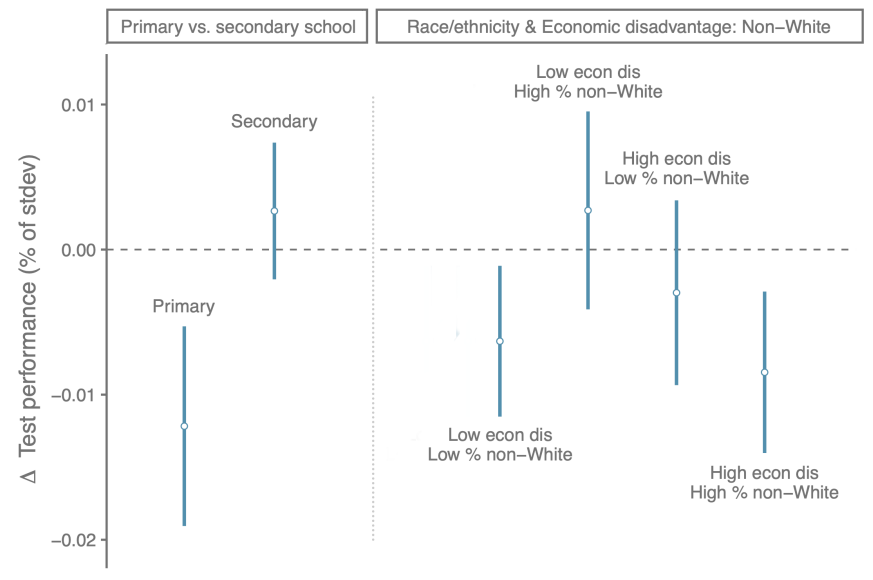

Figure 3: Heterogeneous effects of school day smoke $\mathrm{PM}_{2.5}$ on test performance by grade, race/ethnicity, and level of economic disadvantage. Additional smoke $\mathrm{PM}_{2.5}$ appear to impact primary school (grades 3-5) students more negatively than secondary school (grades 6-8) students. The right panel shows the point estimates and $95 \%$ confidence intervals for different intersecting levels of economic disadvantage and non-White racial-ethnic student population. The negative impacts of smoke $\mathrm{PM}_{2.5}$ appear more pronounced for districts with high economic disadvantage and high non-White student population. out the racial-ethnic subgroups we find that districts with a greater proportion of Asian, Black, or Hispanic students exhibit similar patterns of response to additional school day smoke $\mathrm{PM}_{2.5}$ exposure as opposed to districts with a greater proportion of White students (Supplemental Figure 1).

To understand nation-wide impacts of less severe versus more severe average smoke years on learning, we compared the 2011 versus 2016 school years, the former being the least smoky on average across districts and the latter being the most smoky year in our sample - albeit much less smoky than either 2018 or 2020 , which are not in our sample. Taking into account heterogeneity in economic and racial-ethnic composition across school districts, we find substantial impacts of smoke exposure on learning across broad swaths of the US (Figure 4A), including large extremes in the West, Midwest, and Northeast driven by fires in the Western United States and Canada. If smoke years continue to mirror the severity of 2011, we would expect students to experience a decrease of $0.031 \%$ of a standard deviation in average test scores (median across districts), relative to a counterfactual of no smoke. On the other hand, if wildfire events are more similar to a severe smoke year, like the one in 2016, the median effect would be nearly an order of magnitude larger at $0.207 \%$ of a standard deviation decrease in average test scores. These impacts are again noticeable across all regions (Figure 4), but especially severe across the West.

As a rough estimate of the economic impact of cumulative smoke $\mathrm{PM}_{2.5}$ exposure during the school year, we follow Park et al. (2020) [34] and calculate smoke impacts in terms of lost future earnings for students in our sample (Methods). We apply estimates from Chetty et al. (2014) [50], who found that a 1 standard deviation increase in teacher quality raised average tests scores by 0.13 standard deviations and resulted in a net present value of $\$ 7,000$ in future increased earnings for 12 year-old students. Using this relationship, we estimate that district-average smoke $\mathrm{PM}_{2.5}$ exposure led to a reduction in the net present value of lost future earnings of $\sim \$ 111$ per student in 2016 compared to $\sim \$ 17$ in 2011 . The lost earnings of $\sim \$ 111$ per student in 2016 totals nearly $\$ 1.7$ billion in potential lost future income from smoke $\mathrm{PM}_{2.5}$ exposure when aggregating across all students in the US. We note that these impact estimates assume that increased future earnings due to teacher quality improvements are comparable to benefits of reducing smoke attributable $\mathrm{PM}_{2.5}$ in the classroom. The estimated impacts could be overstated if teacher quality improvements result in other nontest performance related benefits that increase students' future earnings. However, impacts of this magnitude illustrate the potential benefits of reducing wildfire smoke $\mathrm{PM}_{2.5}$ exposure.

When we consider the cumulative losses over all study years and across subgroups (Figure 4B), we estimate net present value of lost future income of roughly $\$ 544$ million (95\% CI: $-\$ 999$ million to -\$100 million) from smoke $\mathrm{PM}_{2.5}$ exposure in 2016 for districts with low economic disadvantage and low proportion of non-White students. For districts with high economic disadvantage and high proportion of non-White students, we estimate cumulative impacts of $\$ 1.4$ billion (95\% CI: $-\$ 2.3$ billion to $-\$ 477$ million) from cumulative smoke $\mathrm{PM}_{2.5}$ exposure in 2016. Thus of the roughly $\$ 1.7$ billion in total costs during the smokiest year in our sample, $82 \%$ of the costs we estimate were borne by economically disadvantaged communities of color. The larger total burden in these communities is a function of both the more negative effect size and the relatively larger total number of students that attend schools in economically disadvantaged communities of color.

\section{Discussion}

These results provide previously unaccounted for estimates of the negative impacts of smoke $\mathrm{PM}_{2.5}$ exposure on test performance. Our study quantifies the impact of wildfire-smokeattributable $\mathrm{PM}_{2.5}$ exposure, a rapidly growing source of particulate exposure throughout much of the US and one which is expected to further increase as the climate warms [28]. We leverage a large time-series with test scores from school districts across the United States and a novel method for isolating smoke-attributable particulate matter and find that the negative impact of smoke exposure is present across test subjects, appears stronger on days in which kids are in school, and affects communities with differing levels of economic disadvantage and racial-ethnic composition. While test scores are an imperfect measure of student cognition, they are a common metric for evaluating student learning with relevance for long-term outcomes and opportunities $[13,50,16]$. The effects of smoke on school days suggests that smoke-related air pollution affects students' ability to learn in the classroom, and that these learning deficits ultimately affect their test performance.

Our findings add to a set of previous studies that have examined the effect of other environmental exposures on student learning and test performance. In a study of heat on learning, an additional day with temperatures above $80^{\circ} \mathrm{F}\left(26.7^{\circ} \mathrm{C}\right)$ during the school year was found to decrease average test scores by $0.07 \%$ of a standard deviation [35], which was a little over twice our estimated impact of an average $\left(6 \mu \mathrm{g} / \mathrm{m}^{3}\right)$ smoky day. Because there were on average more school days across the US with temperature above $80^{\circ} \mathrm{F}$ (32 in their sample) than average 

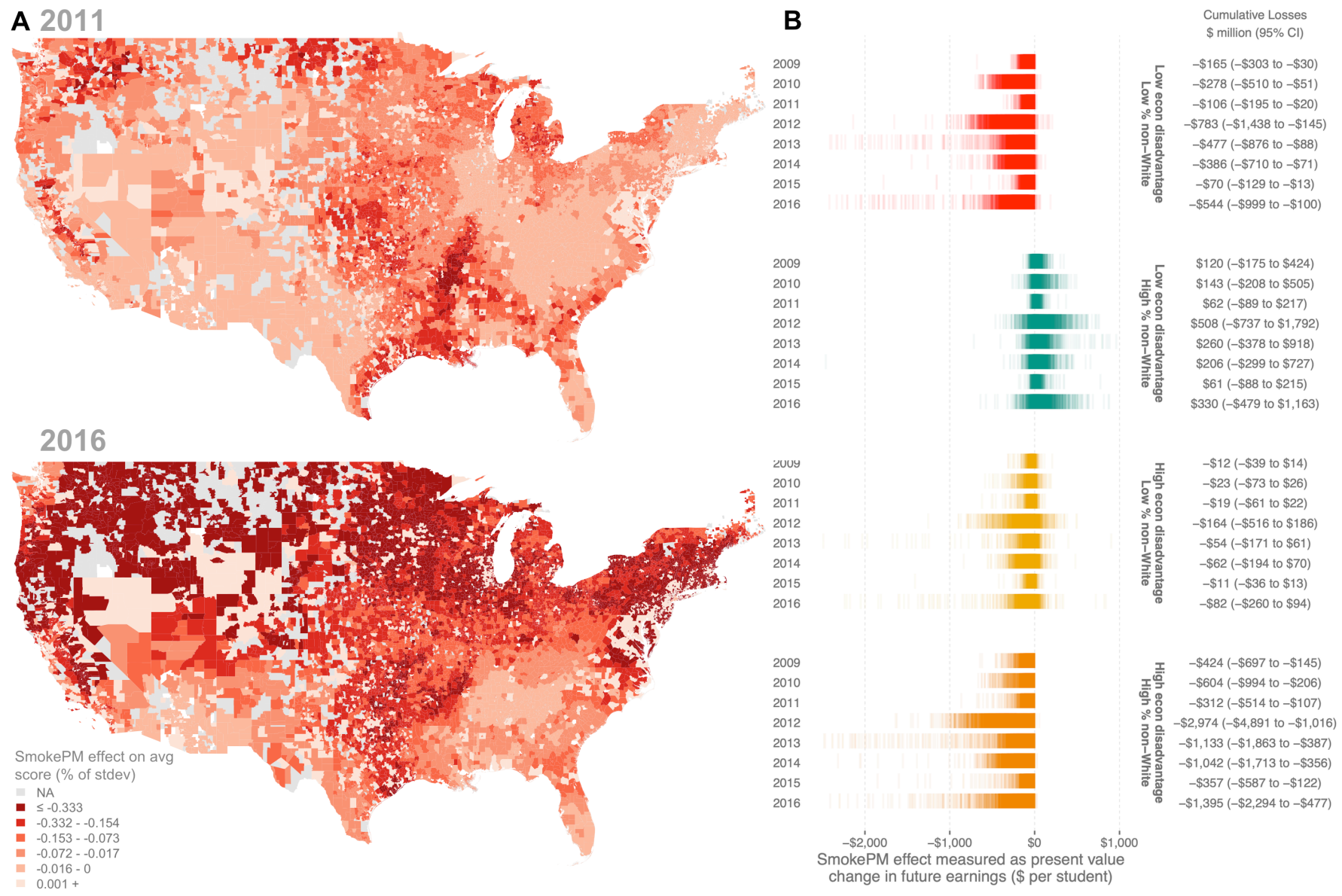

Figure 4: School day smoke $\mathrm{PM}_{2.5}$ effect on average test scores by district, and total effect on lost future earnings by economic disadvantage and racial-ethnic subgroup over time. A. Predicted effect of cumulative smoke $\mathrm{PM}_{2.5}$ exposure during school days on average student test scores in 2011 (top, a relatively low smoke year in our sample) and 2016 (bottom, a relatively high smoke year). In 2016, the West, Midwest, and Northeast experienced large effects from smoke $\mathrm{PM}_{2.5}$ exposure compared to in 2011. B. Effect of school day smoke $\mathrm{PM}_{2.5}$ on the net present value of future earnings separated by year, economic disadvantage, and racial-ethnic subgroup. Each tick mark represents a specific district in the matching year and subgroup (Methods). Cumulative net present value changes in future earnings are provided on the right and represent the total changes in future earnings across all students that fall into the matching year and subgroup, with 5th-95th percentile range across districts in parentheses.

days with smoke in the air in our sample (7 per school year), this suggests that the effects of heat are currently a more important determinant of learning outcomes than smoke. Nevertheless, the number of days with smoke in the air and the average concentration of smoke $\mathrm{PM}_{2.5}$ on smoky days have both increased dramatically in the few years since the end of our study period $[28,47]$, suggesting a growing influence of smoke in more recent years.

In a study of the effect of air pollution exposure on the day of test taking on test performance in Israel, Ebenstein et al. (2016) found that a 1 standard deviation increase in $\mathrm{PM}_{2.5}(\sim 16.7$ (AQI)) led to a $3.9 \%$ of a standard deviation decrease in test scores [13]. Zivin et al. (2020) estimate that a $10 \mu \mathrm{g} / \mathrm{m}^{3}$ increase in $\mathrm{PM}_{2.5}$ on the day of the National College Entrance Examination (NCEE) in China reduces test scores by $4.6 \%$ of a standard deviation [16] In our primary specification, we consider cumulative smoke $\mathrm{PM}_{2.5}$ exposure on school days in the year leading up to the exam period. A 1 standard deviation increase in the cumulative school day smoke $\mathrm{PM}_{2.5}\left(32.5 \mu \mathrm{g} / \mathrm{m}^{3}\right)$ would result in a decrease of $0.14 \%$ (95\% CI: $-0.266 \%$ to $-0.019 \%$ ) a standard deviation. These results suggest that contemporaneous air pollution exposure has an order of magnitude larger effect on test scores compared to smoke $\mathrm{PM}_{2.5}$ exposure in the year prior to the exam. One explanation for this is that, for exposure during the school year, students can catch up on non-smoky days after suffering learning decrements on smoke days; such catch-up is not possible when the exposure is on test day. Together these findings point to the desirability of executing "high stakes" cognitive tasks (e.g. standardized test taking) on days when air pollution from wildfires or other sources is likely to be low, although such avoidance behavior will be difficult for many tasks and increasingly difficult as the number of smoky days increases across the country.

One potential underlying biological mechanism for the observed negative effects of smoke $\mathrm{PM}_{2.5}$ exposure for primary school students compared to secondary school students is that air pollution is more harmful to younger children as their bodies are developing and their quicker breathing leads to increased 
exposure which could ultimately affect their development [46]. Another possibility is that $\mathrm{PM}_{2.5}$ affects students through more absences due to potential health impacts, which ultimately results in reduced learning $[51,52,14]$. Better understanding the mechanism by which younger students are affected will help guide future intervention.

Perhaps surprisingly, we find that estimated effects of smoke on learning are largest in both the least and the most disadvantaged communities. Similar effects at different ends of the disadvantage spectrum could be a result of multiple sources of heterogeneity that each have independent effects across groups. For instance, in districts with high economic disadvantage and high proportion of non-White students, differences in housing or school characteristics - for example, a more permeable building envelope or differences in available filtration - could allow more ambient pollution to infiltrate into and remain in indoor environments [32, 33, 47]. Lower access to air conditioning in disadvantaged schools [34] might also force classrooms to keep windows open, increasing infiltration of wildfire smoke. While limited work on infiltration of wildfire smoke does suggest some role for factors such as income, race/ethnicity, and housing quality in predicting infiltration into homes [47, 33] more widespread measurement in schools will be needed to understand whether differential infiltration can help explain the heterogeneous results we find.

One potential explanation for the observed negative impacts in low disadvantage communities is if the marginal effect of additional exposure declines at higher baseline $\mathrm{PM}_{2.5}$ exposure Such a non-linear relationship has been documented in health impacts studies of wildfire specifically [53] and air pollution more broadly [54,55], and could be explained as the result of adaptive investments in communities accustomed to higher average exposures, or alternatively as the relative importance of other determinants of learning (e.g. school funding or teacher quality) that happen to be correlated with baseline pollution exposure Indeed, we find that the effects of smoke $\mathrm{PM}_{2.5}$ exposure are more negative for districts with lower average baseline $\mathrm{PM}_{2.5}$ levels (Supplemental Figure 2). Additionally, a majority of districts with low economic disadvantage and low proportion of non-White students within our sample are in the lowest baseline $\mathrm{PM}_{2.5}$ bin (Supplemental Table 3). However, because other subgroups also appear to have many districts in the lowest baseline $\mathrm{PM}_{2.5}$ bin, this explanation is also unlikely to fully explain the heterogeneous effects we find.

Nevertheless, although both Whiter/wealthier and less White/ less wealthy communities experience similarly negative impacts per student, we find that the overall burden in terms of total lost earnings is borne mostly by disadvantaged districts of color because these districts make up around 50\% of the exposed students in our sample. This suggests that additional increases in future wildfire smoke exposure due to climate change will likely disproportionately harm these communities, and that investments in wildfire risk reduction (e.g through fuels management) could have large benefits in these communities.

We also find important regional differences that result from where smoke travels, although these differences can change year by year. For instance, while the Northeast experienced relatively less smoke in the 2011 school year, smoke $\mathrm{PM}_{2.5}$ exposure was much higher in 2016. This could be due to wildfires in Canada, which generate large amounts of smoke, and meteorological conditions that transport smoke over great distances as in previously documented wildfire events $[56,57]$. As wildfires continue to increase due to climate change, regions that had previously experienced relatively mild smoke events could begin to see more wildfire smoke from regions far away even across national boundaries [28].

Estimates of the present value of lost future earnings due to decreased learning outcomes resulting from smoke exposure suggest that in very smoky years, wildfire-attributable-smoke $\mathrm{PM}_{2.5}$ would effectively decrease the net present value of future earnings by $\$ 55,500$ per school (for a school with 500 students) and by nearly $\$ 1.7$ billion across the US, with $\sim 80 \%$ of these impacts in disadvantaged communities of color. These calculations assume that the relationship between test scores and future earnings reported in Chetty et al. (2014) holds for smoke exposure. Chetty et al. (2014) focuses on the effects of improved teacher quality on test performance and eventual earnings [50], which could be different from the effects studied here as improvement in teacher quality could lead to more than just test score increases. If this is the case, then our estimates would overstate the impact of smoke $\mathrm{PM}_{2.5}$ on future income. Nevertheless, while these are rough calculations, as wildfires and the associated smoke events increasingly affect school districts across the US, estimates like these can inform cost-benefit analyses of investments aimed at reducing smoke $\mathrm{PM}_{2.5}$ exposures.

Although the combined effect of smoke $\mathrm{PM}_{2.5}$ exposure is smaller than the identified school day smoke exposure effect, the amount of smoke $\mathrm{PM}_{2.5}$ on non-school days (includes summer months) is much greater than the amount of smoke $\mathrm{PM}_{25}$ on school days. When we consider the combined effect of smoke exposure (school and non-school days) and conduct a similar calculation as shown in Figure 4B, we find much larger estimated impacts across all years and subgroups (Supplemental Figure 4). However, as we cannot be sure that students remain around their school districts during summer months and other non-school days, our analysis primarily focuses on school day exposures.

Compared to using satellite-derived smoke plume annotations alone, our approach provides improved estimates of smokeattributable $\mathrm{PM}_{2.5}$ by combining annotations with predicted $\mathrm{PM}_{2.5}$ data to separate smoke $\mathrm{PM}_{2.5}$ from background $\mathrm{PM}_{2.5}$. However, the smoke plume annotations could be noisy because they are drawn over multiple hours and usually only a couple of times per day [57]. Future work to improve the precision of the smoke annotations could lead to more precise estimates of smoke attributable $\mathrm{PM}_{2.5}$. Additionally, we currently do not account for the specific district test taking dates and instead remove any smoke observations between March - May. The exposure calculation could be improved (where possible) by compiling district specific testing dates, which would allow us to more precisely measure the full period of exposure in the year prior to the exam.

Our work contributes to a growing body of evidence demonstrating the cognitive, health, and social harms of air pollution in general, and wildfires specifically, and shows how disparities in these impacts across socioeconomic and racial-ethnic groups can emerge even when there are negligible differences across groups in ambient exposures. Our estimates also uncover yet another substantial cost of a warming climate, with future 
warming-driven increases in wildfire activity likely to worsen learning outcomes.

\section{Methods}

\section{Measuring wildfire-smoke-attributable $P M_{2.5}$}

To generate estimates of wildfire-smoke-attributable $\mathrm{PM}_{2.5}$ across all school districts for all study years, we merge satellite derived smoke plume data from the National Environmental Satellite, Data, and Information Service (NESDIS) Hazard Mapping System (HMS) with gridded estimates of daily $\mathrm{PM}_{2.5}$ concentrations from Di et al. (2021) $[40,41]$. We then estimate smoke-attributable $\mathbf{P M}_{2.5}$ as location- and period-specific anomalous $\mathrm{PM}_{2.5}$ on days in which the plume data indicated that smoke was overhead. Plume data derive from manual annotations by trained analysts, using a variety of remote sensing products including visible-band imagery from NOAA's GOES satellites multiple times per day across the US [57]. In total we use nearly 200,000 individual smoke plumes between 2008-2016.

The predicted $\mathrm{PM}_{2.5}$ data $[40,41]$ is provided as daily $\mathrm{PM}_{2.5}$ concentrations for all-source $\mathrm{PM}_{2.5}$ (not just wildfire $\mathrm{PM}_{2.5}$ ) for the Contiguous United States in a 1 kilometer grid from 2000 - 2016. The predictions are made using an ensemble of 3 machine learning models including neural networks, random forests, and gradient boosted trees. Each of the models includes multiple explanatory variables including satellite observations, land-use variables, chemical transport predictions, and other variables. The authors note that the ensemble model achieved performance of $r^{2}=0.86$ for daily $\mathrm{PM}_{2.5}$ predictions. To isolate $\mathrm{PM}_{2.5}$ from wildfires, we follow [47] and calculate smoke-attributable $\mathrm{PM}_{2.5}$ as the deviation from location-specific median $\mathrm{PM}_{2.5}$ on non-smoke days in the same month, with the median calculated over a 3-year window centered on the current year. Specifically, the smoke-attributable $\mathrm{PM}_{2.5}$ anomaly is calculated by subtracting the month-specific 3-year non-smoke day median estimated from the predicted $\mathrm{PM}_{2.5}$ at each school district on days with a smoke plume overhead. After we obtain the smoke $\mathrm{PM}_{2.5}$ anomalies, we set this smoke $\mathrm{PM}_{2.5}$ variable to 0 for non-smoke days and the positive anomaly for days with a plume overhead. Smoke days with negative anomaly values were also set to 0 The resulting measure of smoke $\mathrm{PM}_{2.5}$ isolates the smoke component of overall $\mathrm{PM}_{2.5}$ so long as, on average, other $\mathrm{PM}_{2.5}$ sources are not also anomalously high on days when smoke is in the air - a plausible assumption given the large degree of temporal and spatial randomness in when and where fires start and where plumes go.

\section{Assigning smoke $P M_{2.5}$ exposure to school districts}

We calculate a student-population weighted average of school level exposure to estimate aggregate exposure at the district level. We further delineate school day exposure versus non-school day exposure, specifying non-school days as weekends and federal bank holidays throughout the year and all days from June 15 to August 15. Because standardized testing in the US is conducted at various points throughout the Spring, usually between March and May, our analysis focuses on exposures from the previous June to February. For this analysis, we focus on school years between $2009-2016$ as the predicted $\mathrm{PM}_{2.5}$ data is only available between 2000-2016.

\section{Outcome and covariate data}

Test score data were compiled by Stanford University and made available through the Stanford Education Data Archive (SEDA) [58] The SEDA team constructed the dataset by converting state-specific proficiency data to a nationally comparable dataset by scaling the state results using a nationally representative sample from the National Assessment of Educational Progress (NAEP). For specific details about how the dataset was created and the calculations involved in scaling the state scores to a national dataset, we direct interested readers to [58]. The SEDA data contains nationally comparable test scores for students in grades 3-8 from 2009-2018. These test scores are broken down into district-level results for both math and English language arts (ELA) subjects. Rather than represent an absolute score, the metric provided in the dataset is a standardized score within subject and grade, relative to representative cohorts who had taken the NAEP assessments [49]. Therefore, a score of 0.25 for Math means that an average student in that district performed 0.25 of a standard deviation higher than the reference cohort that took the NAEP assessment. The primary outcome we consider is the average test score between ELA and math at the district level.

In addition to calculating an average treatment effect across aggregated data in our main model specification, we also investigate heterogeneous effects using district-level racial-ethnic and economic disadvantage covariates. Specifically, the level of economic disadvantage is measured by the Federal EdFacts data system and is typically defined using the proportion of students eligible for free or reduced-price lunch [48]. The proportion of non-White students in a district is calculated by subtracting the proportion of White students from 1 where the proportion of White students is collected by the Common Core of Data (CCD) and aggregated by the SEDA team to the district level [49].

We use gridded $(4 \mathrm{~km} \times 4 \mathrm{~km})$ temperature and precipitation data produced by the Parameter elevation Regressions on Independent Slopes Model (PRISM) Climate Group at Oregon State University [42]. We extract the max daily temperature at each school and take a weighted average using the student population at the schools that belong to that district. As with the weighting for smoke exposure, the student population data was collected from the National Center for Education Statistics (NCES). We then create bins by counting the number of days in the year prior to the exam with max temperatures in $10^{\circ} \mathrm{F}\left(5.5^{\circ} \mathrm{C}\right)$ increments from $0^{\circ} \mathrm{F}\left(-17.7^{\circ} \mathrm{C}\right)$ to $80^{\circ} \mathrm{F}\left(26.7^{\circ} \mathrm{C}\right)$. All days less than or equal to $0^{\circ} \mathrm{F}\left(-17.7^{\circ} \mathrm{C}\right)$ are grouped into 1 bin and all days greater than $80^{\circ} \mathrm{F}\left(26.7^{\circ} \mathrm{C}\right)$ are grouped into another bin. We process the daily precipitation data similarly and extract the daily precipitation measurements at each school then calculate the total annual precipitation at the district level.

\section{Estimating the effect of smoke PM 2.5 on student performance}

$$
\begin{gathered}
\text { Score }_{i g y}=\beta_{1} \text { SmokePM }_{i y}^{\text {school }}+\beta_{2} \text { SmokePM }_{i y}^{\text {non-school }} \\
+f\left(\mathbf{X}_{i y}\right)+\eta_{i}+\gamma_{y g}+\epsilon_{i g y}
\end{gathered}
$$

Here, Score represents the scaled standardized score for each district $i$ in grade $g$, and year $y$. The district fixed effect $\eta_{i}$ is a separate intercept (dummy variable) for each district that accounts for any average differences in smoke exposure or test scores across districts. This empirical approach ensures that we are not comparing districts that might inherently be very different from each other. The grade-year fixed effects $\gamma_{y g}$ account for differences in year-grade specific exposures or outcomes that affect all districts across the US, such as overall trends in test scores or in average differences between test scores across grades. $f(\mathbf{X})$ represents a vector of controls including the number of days with max temperatures in each of the $10^{\circ} \mathrm{F}\left(5.5^{\circ} \mathrm{C}\right)$ bins, which controls for potential non-linear effects of temperature within the district for the year preceding the test, and total annual precipitation in the year prior to the exam. SmokePM is defined as the total amount of smoke-attributable $\mathrm{PM}_{2.5}$ in the year prior to the exam in our primary specification. We define SmokePM ${ }^{\text {school }}$ and SmokePM ${ }^{\text {non-school }}$ as the total cumulative smoke $\mathrm{PM}_{2.5}$ in a preceding year $y$ within district $i$ between June and February on school and non-school days respectively. $\beta_{1}$ represents the 
average effect of an additional $\mu \mathrm{g} / \mathrm{m}^{3}$ of cumulative smoke $\mathrm{PM}_{2.5}$ on school days on test performance. $\beta_{2}$ represents the average effect of an additional $\mu \mathrm{g} / \mathrm{m}^{3}$ of cumulative smoke $\mathrm{PM}_{2.5}$ on non-school days on test performance. To estimate the subject specific coefficient estimates (Figure 2B), we replace mean score Score $_{i g y}$ with the subject specific scores and consider the cumulative SmokePM (both school and non-school) in the year prior to the exam. We cluster standard errors by county to account for arbitrary within-unit autocorrelation in $\epsilon_{i g y}$ and weight districts by the total number of students who took the test provided in the SEDA dataset.

We also conduct secondary analyses (equation 2) looking at the heterogeneous effects of smoke exposure on test outcomes. To examine these effects, we study whether the effects of smoke $\mathrm{PM}_{2.5}$ differ across different grade levels and a combination of economic disadvantage and race-ethnicity, using the following specification:

$$
\begin{aligned}
\text { Score }_{i g y}=\sum_{n} & \beta_{n}\left(\mathbb{1}_{n} * \mathrm{SmokePM}_{i y}^{\text {school }}\right) \\
& +\sum_{n} \beta_{n}\left(\mathbb{1}_{n} * \mathrm{SmokePM}_{i y}^{\text {non-school }}\right) \\
& +f\left(\mathbf{X}_{i y}\right)+\eta_{i}+\gamma_{y g}+\epsilon_{i g y}
\end{aligned}
$$

Here, $\mathbb{1}_{n}$ represents an indicator function for whether or not the observation $i$ falls into a specific bin $n$. To determine these bins, we divide districts into "High" or "Low" categories based on thresholding at the median value for race-ethnicity and economic disadvantage variables. The remainder of the equation is similar to equation 1 .

\section{Calculating the effect of smoke $P M_{2.5}$ in terms of lost future income}

To translate the effect estimates into the net present value of lost future earnings, we follow the approach used in Park et al. (2020) [34]. Specifically, we assume the relationship found in Chetty et al. (2014) [50] holds, which estimated that a 1 standard deviation increase in teacher quality raised average tests scores by 0.13 standard deviations and resulted in a net present value of $\$ 7,000$ in future increased earnings for 12 year-old students. Therefore, if the estimated effect of an additional $\mu \mathrm{g} / \mathrm{m}^{3}$ of smoke $\mathrm{PM}_{2.5}$ is a decrease of $0.01 \%$ of a standard deviation and the average smoke $\mathrm{PM}_{2.5}$ experienced in a year is $10 \mu \mathrm{g} / \mathrm{m}^{3}$, then we calculate the average effect as $0.01 \% \times 10=0.1 \%$. We can then apply the Chetty et al. (2014) conversion and calculate that $\frac{0.001 \times 7000}{0.13}=\$ 53.85$ on average per student for that year of smoke $\mathrm{PM}_{2.5}$ exposure.

In panel B of Figure 4, we plot the average net present value change in future earnings for each district as an individual tick mark, calculated as described above. For each of the four economic disadvantage and racialethnic subgroups, we draw 3000 samples from a normal distribution with mean centered at the matching subgroup coefficient (equation 2) and standard deviation set to the estimated standard error. We then merge this with district information by matching on the districts subgroup for each year. From this data, we estimate the district specific average impacts by year and we sample 1 observation out of the 3000 to show as a tick mark. Additionally, we use the sampled data to estimate $95 \%$ interval estimates for the cumulative changes in net present value of future earnings.

\section{Calculate distance to nearest fire perimeter}

We calculate distances from schools to the nearest fire perimeter in each year provided by the National Interagency Fire Center [59]. Then, we take an average of the minimum school-to-fire distances to get estimates of the average distance to the nearest fire for each district. While evacuation zone distances vary, recent studies of wildfire evacuations in California suggest that short-distance evacuations are much more common than longer distance evacuations to destinations outside of the county of residence [60]. Additionally, a 1.5 mile (2.4 kilometer) distance is often cited as the distance that forest fire embers can travel and ignite flammable materials at distant locations beyond the fire front [61]. Given this, we consider dropping school districts within a range of distances from 1-kilometer to 20-kilometers to the nearest fire perimeter and find that the identified effects are consistent up to dropping districts within 10-kilometers of the nearest fire perimeter (Supplemental Figure 3).

\section{REFERENCES}

[1] Thomas Kitzberger, Donald A Falk, Anthony L Westerling, and Thomas W Swetnam. Direct and indirect climate controls predict heterogeneous early-mid 21 st century wildfire burned area across western and boreal north america. PloS one, 12(12):e0188486, 2017.

[2] Philip E Dennison, Simon C Brewer, James D Arnold, and Max A Moritz. Large wildfire trends in the western united states, 19842011. Geophysical Research Letters, 41(8):2928-2933, 2014

[3] Colleen E Reid, Michael Brauer, Fay H Johnston, Michael Jerrett, John R Balmes, and Catherine T Elliott. Critical review of health impacts of wildfire smoke exposure. Environmental health perspectives, 124(9):1334-1343, 2016.

[4] Rosana Aguilera, Thomas Corringham, Alexander Gershunov, and Tarik Benmarhnia. Wildfire smoke impacts respiratory health more than fine particles from other sources: observational evidence from southern california. Nature communications, 12(1): $1-8,2021$.

[5] Lilian Calderón-Garcidueñas, Antonieta Mora-Tiscareño, Esperanza Ontiveros, Gilberto Gómez-Garza, Gerardo Barragán-Mejía, James Broadway, Susan Chapman, Gildardo Valencia-Salazar, Valerie Jewells, Robert R Maronpot, et al. Air pollution, cognitive deficits and brain abnormalities: a pilot study with children and dogs. Brain and cognition, 68(2):117-127, 2008.

[6] Michelle L Block and Lilian Calderón-Garcidueñas. Air pollution: mechanisms of neuroinflammation and cns disease. Trends in neurosciences, 32(9):506-516, 2009.

[7] Dave E Marcotte. Something in the air? air quality and children's educational outcomes. Economics of Education Review, 56:141$151,2017$.

[8] Steffen Künn, Juan Palacios, and Nico Pestel. Indoor Air Quality and Cognitive Performance, 2019.

[9] Jiekun Huang, Nianhang $\mathrm{Xu}$, and Honghai Yu. Pollution and performance: Do investors make worse trades on hazy days? Management Science, 66(10):4455-4476, 2020.

[10] Tom Y Chang, Joshua Graff Zivin, Tal Gross, and Matthew Neidell. The effect of pollution on worker productivity: evidence from call center workers in china. American Economic Journal: Applied Economics, 11(1):151-72, 2019.

[11] James Archsmith, Anthony Heyes, and Soodeh Saberian. Air quality and error quantity: Pollution and performance in a highskilled, quality-focused occupation. Journal of the Association of Environmental and Resource Economists, 5(4):827-863, 2018.

[12] Andrea La Nauze and Edson R. Severnini. Air Pollution and Adult Cognition: Evidence from Brain Training, 2021. URL https://www.nber.org/papers/w28785. National Bureau of Economic Research: Working Paper Series. 
[13] Avraham Ebenstein, Victor Lavy, and Sefi Roth. The long-run economic consequences of high-stakes examinations: Evidence from transitory variation in pollution. American Economic Journal: Applied Economics, 8(4):36-65, 2016.

[14] Victoria Shier, Nancy Nicosia, Regina Shih, and Ashlesha Datar. Ambient air pollution and children's cognitive outcomes. Population and Environment, 40(3):347-367, 2019.

[15] Xin Zhang, Xi Chen, and Xiaobo Zhang. The impact of exposure to air pollution on cognitive performance. Proceedings of the National Academy of Sciences, 115(37):9193-9197, 2018.

[16] Joshua Graff Zivin, Tong Liu, Yingquan Song, Qu Tang, and Peng Zhang. The unintended impacts of agricultural fires: Human capital in china. Journal of Development Economics, 147:102560, 2020.

[17] Wangyang Lai, Shanjun Li, Yanan Li, and Xiaohui Tian. Air pollution and cognitive functions: Evidence from straw burning in china. American Journal of Agricultural Economics, 2021.

[18] Jose Guillermo Cedeño Laurent, Piers MacNaughton, Emily Jones, Anna S Young, Maya Bliss, Skye Flanigan, Jose Vallarino, Ling Jyh Chen, Xiaodong Cao, and Joseph G Allen. Associations between acute exposures to pm2. 5 and carbon dioxide indoors and cognitive function in office workers: a multicountry longitudinal prospective observational study. Environmental Research Letters, 16(9):094047, 2021.

[19] MA Shehab and FD Pope. Effects of short-term exposure to particulate matter air pollution on cognitive performance. Scientific reports, 9(1):1-10, 2019.

[20] Juliana Carneiro, Matthew A Cole, and Eric Strobl. The effects of air pollution on students' cognitive performance: Evidence from brazilian university entrance tests. Journal of the Association of Environmental and Resource Economists, 8(6):1051-1077, 2021.

[21] Lilian Calderón-Garcidueñas, Anna C Solt, Carlos HenríquezRoldán, Ricardo Torres-Jardón, Bryan Nuse, Lou Herritt, Rafael Villarreal-Calderón, Norma Osnaya, Ida Stone, Raquel Garcia, et al. Long-term air pollution exposure is associated with neuroinflammation, an altered innate immune response, disruption of the blood-brain barrier, ultrafine particulate deposition, and accumulation of amyloid $\beta$-42 and $\alpha$-synuclein in children and young adults. Toxicologic pathology, 36(2):289-310, 2008.

[22] Pengfei Fu, Xinbiao Guo, Felix Man Ho Cheung, and Ken Kin Lam Yung. The association between pm2. 5 exposure and neurological disorders: A systematic review and meta-analysis. Science of the Total Environment, 655:1240-1248, 2019.

[23] Jordi Sunyer, Mikel Esnaola, Mar Alvarez-Pedrerol, Joan Forns, Ioar Rivas, Mònica López-Vicente, Elisabet Suades-González, Maria Foraster, Raquel Garcia-Esteban, Xavier Basagaña, et al. Association between traffic-related air pollution in schools and cognitive development in primary school children: a prospective cohort study. PLoS medicine, 12(3):e1001792, 2015.

[24] Wenxin Lu, Daniel A Hackman, and Joel Schwartz. Ambient air pollution associated with lower academic achievement among us children: a nationwide panel study of school districts. Environmental Epidemiology, 5(6), 2021.

[25] Michael Gilraine. Air filters, pollution and student achievement. Working paper available at http://www.edworkingpapers.com/ai20-188, January 2020. URL http: //www.edworkingpapers.com/ai20-188.

[26] Jia Coco Liu, Ander Wilson, Loretta J Mickley, Francesca Dominici, Keita Ebisu, Yun Wang, Melissa P Sulprizio, Roger D Peng, Xu Yue, Ji-Young Son, et al. Wildfire-specific fine particulate matter and risk of hospital admissions in urban and rural counties. Epidemiology (Cambridge, Mass.), 28(1):77, 2017.
[27] Rosana Aguilera, Thomas Corringham, Alexander Gershunov, and Tarik Benmarhnia. Wildfire smoke impacts respiratory health more than fine particles from other sources: observational evidence from southern california. Nature communications, 12(1): $1-8,2021$.

[28] Marshall Burke, Anne Driscoll, Sam Heft-Neal, Jiani Xue, Jennifer Burney, and Michael Wara. The changing risk and burden of wildfire in the united states. Proceedings of the National Academy of Sciences, 118(2), 2021.

[29] Jennifer R Marlon, Patrick J Bartlein, Daniel G Gavin, Colin J Long, R Scott Anderson, Christy E Briles, Kendrick J Brown, Daniele Colombaroli, Douglas J Hallett, Mitchell J Power, et al. Long-term perspective on wildfires in the western usa. Proceedings of the National Academy of Sciences, 109(9):E535-E543, 2012.

[30] Anthony L Westerling, Hugo G Hidalgo, Daniel R Cayan, and Thomas W Swetnam. Warming and earlier spring increase western us forest wildfire activity. science, 313(5789):940-943, 2006

[31] Jonathan Colmer, Ian Hardman, Jay Shimshack, and John Voorheis. Disparities in pm2. 5 air pollution in the united states. Science, 369(6503):575-578, 2020.

[32] Wanyu R Chan, Jeffrey Joh, and Max H Sherman. Analysis of air leakage measurements of us houses. Energy and Buildings, 66 : 616-625, 2013

[33] Yutong Liang, Deep Sengupta, Mark J. Campmier, David M Lunderberg, Joshua S. Apte, and Allen H. Goldstein. Wildfire smoke impacts on indoor air quality assessed using crowdsourced data in california. Proceedings of the National Academy of Sciences, 118(36), 2021. ISSN 0027-8424. doi: 10.1073/ pnas.2106478118. URL https://www.pnas.org/content/ 118/36/e2106478118.

[34] R Jisung Park, Joshua Goodman, Michael Hurwitz, and Jonathan Smith. Heat and learning. American Economic Journal: Economic Policy, 12(2):306-39, 2020.

[35] R Jisung Park, A Patrick Behrer, and Joshua Goodman. Learning is inhibited by heat exposure, both internationally and within the united states. Nature human behaviour, 5(1):19-27, 2021.

[36] Christopher W Tessum, Joshua S Apte, Andrew L Goodkind, Nicholas Z Muller, Kimberley A Mullins, David A Paolella, Stephen Polasky, Nathaniel P Springer, Sumil K Thakrar, Julian D Marshall, et al. Inequity in consumption of goods and services adds to racial-ethnic disparities in air pollution exposure. Proceedings of the National Academy of Sciences, 116(13): 6001-6006, 2019.

[37] Jason G Su, Michael Jerrett, Rachel Morello-Frosch, Bill M Jesdale, and Amy D Kyle. Inequalities in cumulative environmental burdens among three urbanized counties in california. Environment international, 40:79-87, 2012.

[38] FW Lipfert. Air pollution and poverty: Does the sword cut both ways? Journal of Epidemiology and Community Health, 58(1):2, 2004.

[39] Cristina Legot, Bruce London, and John Shandra. Environmental ascription: High-volume polluters, schools, and human capital. Organization $\mathcal{E}$ Environment, 23(3):271-290, 2010.

[40] Qian Di, Heresh Amini, Liuhua Shi, Itai Kloog, Rachel Silvern, James Kelly, M. Benjamin Sabath, Christine Choirat, Petros Koutrakis, Alexei Lyapustin, and et al. An ensemble-based model of pm2.5 concentration across the contiguous united states with high spatiotemporal resolution. Environment International, 130 104909, Sep 2019. doi: 10.1016/j.envint.2019.104909. URL http://dx.doi.org/10.1016/j.envint.2019.104909. 
[41] Q. Di, Y. Wei, A. Shtein, C. Hultquist, X. Xing, H. Amini, L. Shi, I. Kloog, R. Silvern, J. Kelly, and et al. Daily and annual pm2.5 concentrations for the contiguous united states, 1-km grids, v1 (2000 - 2016), 2021. URL https: //sedac.ciesin.columbia.edu/data/set/aqdh-pm2-5concentrations-contiguous-us-1-km-2000-2016.

[42] Oregon State University PRISM Climate Group. PRISM Gridded Climate Data, 2019. accessed 2 March 2020; https://prism.oregonstate.edu.

[43] Alberto Abadie, Susan Athey, Guido W Imbens, and Jeffrey Wooldridge. Clustering as a design problem. Working paper available at http://economics.mit.edu/files/11355, 2016.

[44] Christopher Blattman, Donald P Green, Daniel Ortega, and Santiago Tobón. Place-based interventions at scale: The direct and spillover effects of policing and city services on crime. Journal of the European Economic Association, 19(4):2022-2051, 2021.

[45] Casey Mullen, Sara E Grineski, Timothy W Collins, and Daniel L Mendoza. Effects of pm2.5 on third grade students' proficiency in math and english language arts. International Journal of Environmental Research and Public Health, 17(18):6931, 2020.

[46] Sam Brockmeyer and Amedeo d'Angiulli. How air pollution alters brain development: the role of neuroinflammation. Translational neuroscience, 7(1):24-30, 2016.

[47] Marshall Burke, Sam Heft-Neal, Jessica Li, Anne Driscoll, Patrick Baylis, Matthieu Stigler, Jennifer Burney, Jeff Wen, Carlos Gould, et al. Exposures and Behavioral Responses to Wildfire Smoke, 2021. NBER Working Paper.

[48] Sean F Reardon. Educational opportunity in early and middle childhood: Using full population administrative data to study variation by place and age. RSF: The Russell Sage Foundation Journal of the Social Sciences, 5(2):40-68, 2019.

[49] Erin M Fahle, Belen Chavez, Demetra Kalogrides, Benjamin R Shear, Sean F Reardon, and Andrew D Ho. Stanford Education Data Archive Technical Documentation Version 4.0 February 2021, 2021.

[50] Raj Chetty, John N Friedman, and Jonah E Rockoff. Measuring the impacts of teachers ii: Teacher value-added and student outcomes in adulthood. American economic review, 104(9):2633-79, 2014.

[51] Janet Currie, Eric A Hanushek, E Megan Kahn, Matthew Neidell, and Steven G Rivkin. Does pollution increase school absences? The Review of Economics and Statistics, 91(4):682-694, 2009.

[52] Paul Mohai, Byoung-Suk Kweon, Sangyun Lee, and Kerry Ard. Air pollution around schools is linked to poorer student health and academic performance. Health Affairs, 30(5):852-862, 2011.

[53] Sam Heft-Neal, Anne Driscoll, Wei Yang, Gary Shaw, and Marshall Burke. Associations between wildfire smoke exposure during pregnancy and risk of preterm birth in california. Environmental Research, 203:111872, 2022.

[54] Richard Burnett, Hong Chen, Mieczysław Szyszkowicz, Neal Fann, Bryan Hubbell, C Arden Pope, Joshua S Apte, Michael Brauer, Aaron Cohen, Scott Weichenthal, et al. Global estimates of mortality associated with long-term exposure to outdoor fine particulate matter. Proceedings of the National Academy of Sciences, 115(38):9592-9597, 2018.

[55] Tatyana Deryugina, Garth Heutel, Nolan H Miller, David Molitor, and Julian Reif. The mortality and medical costs of air pollution: Evidence from changes in wind direction. American Economic Review, 109(12):4178-4219, 2019.

[56] Vincent A Dutkiewicz, Liaquat Husain, Utpal K Roychowdhury, and Kenneth L Demerjian. Impact of canadian wildfire smoke on air quality at two rural sites in ny state. Atmospheric environment, 45(12):2028-2033, 2011.

[57] Steven J. Brey, Mark Ruminski, Samuel A. Atwood, and Emily V. Fischer. Connecting smoke plumes to sources using hazard mapping system (hms) smoke and fire location data over north america. Atmospheric Chemistry and Physics, 18(3):1745-1761, 2018. doi: 10.5194/acp-18-1745-2018. URL https://www.atmos-chemphys.net/18/1745/2018/.

[58] Sean F. Reardon, Andrew D. Ho, Benjamin R. Shear, Erin M. Fahle, Demetra Kalogrides, Heewon Jang, and Belen Chavez. Stanford education data archive (version 4.0), 2021. URL http: //purl.stanford.edu/db586ns4974.

[59] National Interagency Fire Center - Wildland Fire Management Research, Development, \& Application program data team. Interagency Fire Perimeter History - All Years, 2021. accessed 30 January 2021; https://datanifc.opendata.arcgis.com/datasets/nifc::interagency-fireperimeter-history-all-years/about.

[60] Stephen D Wong, Jacquelyn C Broader, and Susan A Shaheen Review of california wildfire evacuations from 2017 to 2019. UC Office of the President: University of California Institute of Transportation Studies., 2020.

[61] Volker C Radeloff, Roger B Hammer, Susan I Stewart, Jeremy S Fried, Sherry S Holcomb, and Jason F McKeefry. The wildlandurban interface in the united states. Ecological applications, 15 (3):799-805, 2005. 


\section{Supplementary Information for}

2 Wildfire Smoke Exposure Worsens Learning Outcomes

3 Jeff Wen and Marshall Burke

4 Jeff Wen

$5 \quad$ E-mail: jlwen@stanford.edu

6 This is the supplementary information for a non-peer reviewed preprint submitted to EarthArXiv. It has been submitted for 7 publication in a peer reviewed journal, but has yet to be formally accepted for publication.

8 This PDF file includes:

Figs. S1 to S4

Tables S1 to S4 

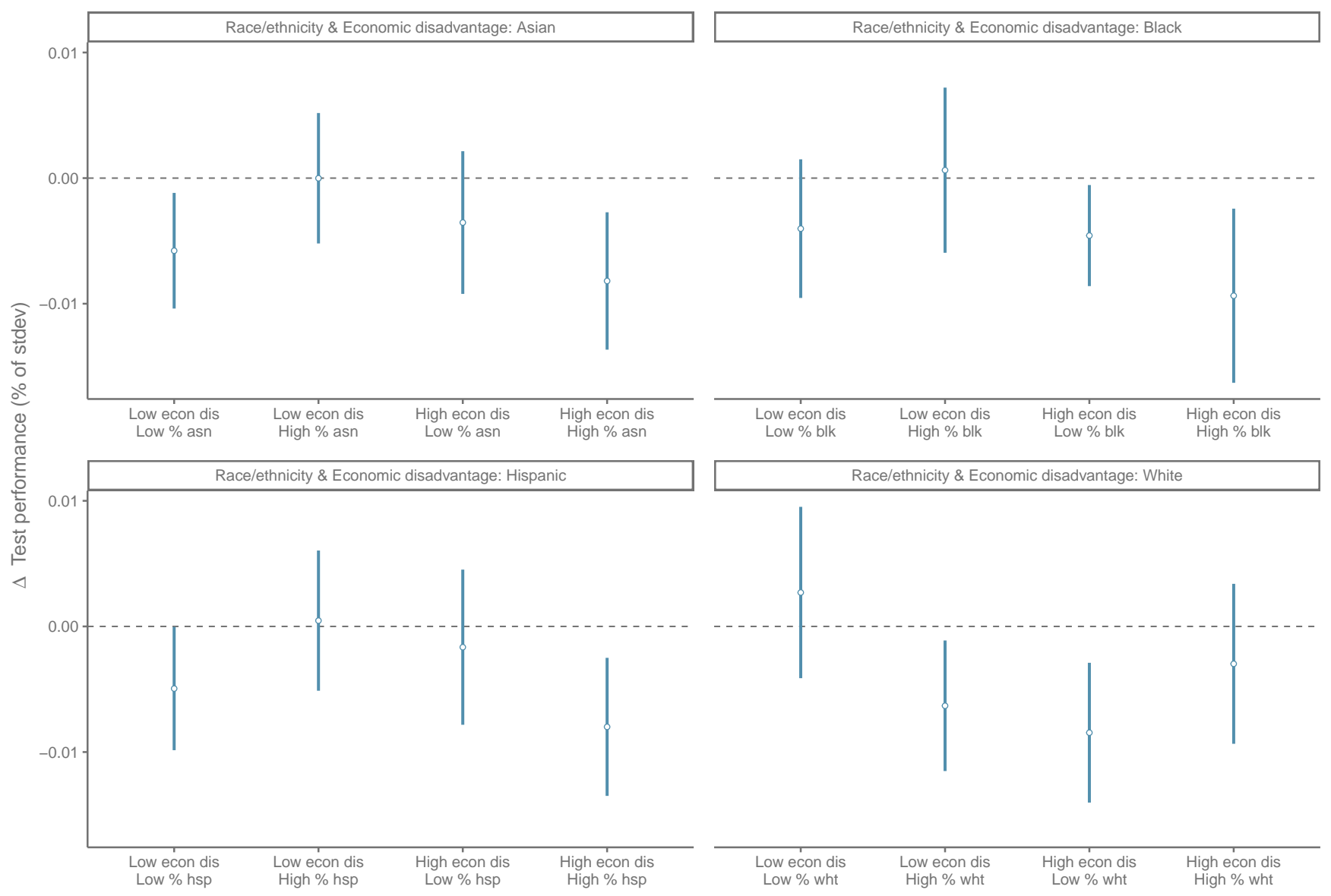

Fig. S1. Effect estimates of additional cumulative school-day smoke $\mathrm{PM}_{2.5}$ exposure across different racial-ethnic groups and levels of economic disadvantage. The bottom right panel shows effect estimates across across different levels of \% White students while the right panel in Figure 3 of the main text shows the complement and subtracts the $\%$ of White students from 1. 


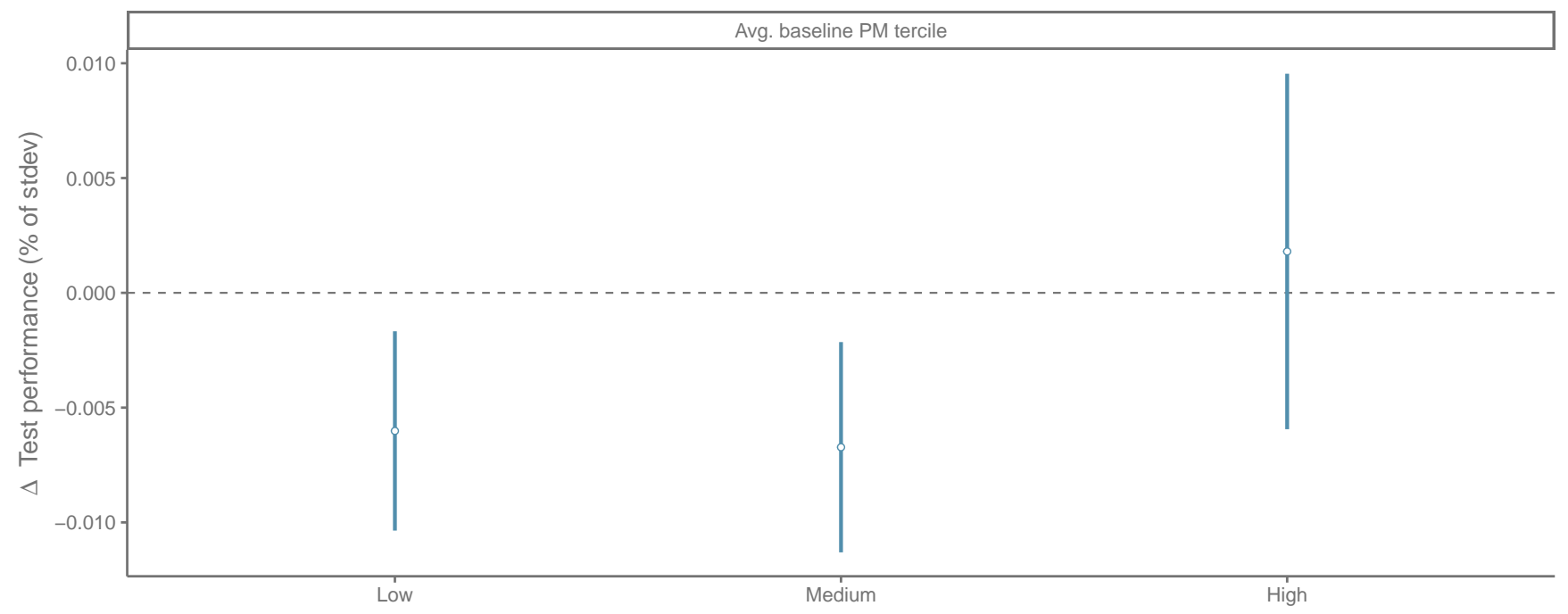

Fig. S2. Effect estimates of additional cumulative school-day smoke PM exposure across different levels of baseline $\mathrm{PM}_{2.5}$. The baseline PM 2.5 bins were determined by calculating the average total $\mathrm{PM}_{2.5}$ for each district and separating into bins based on terciles across our data sample. 


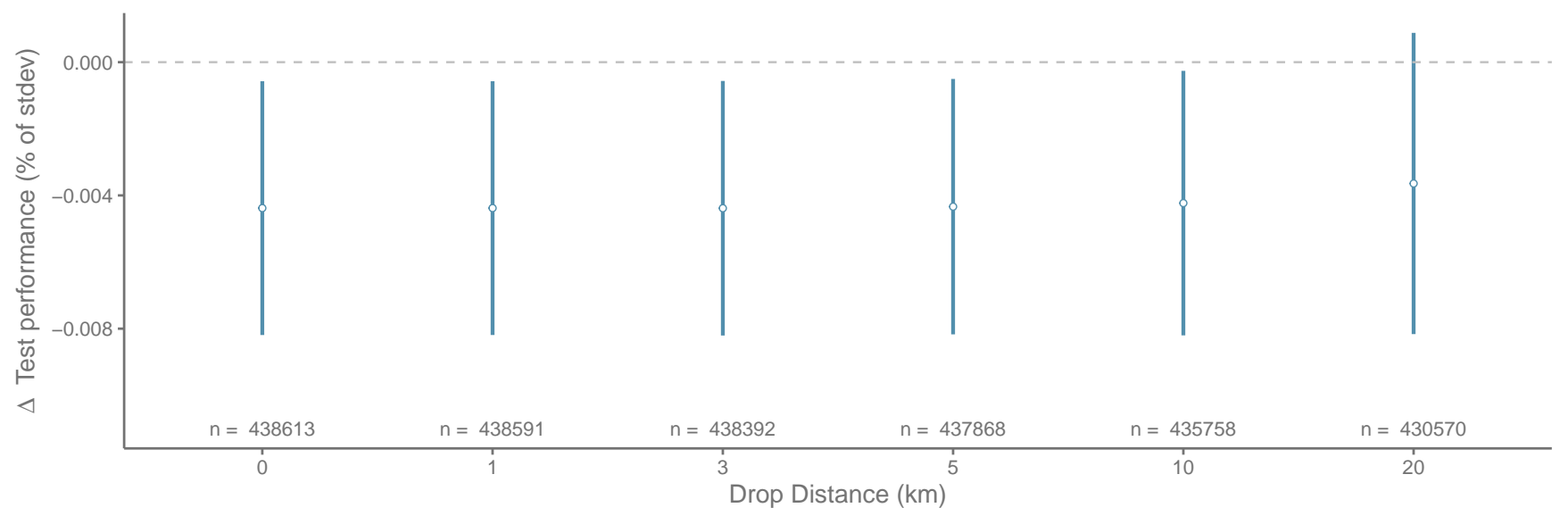

Fig. S3. To test that the identified effects are driven by exposure to wildfire-attributable smoke $\mathrm{PM}_{2.5}$ rather than from the direct wildfire impacts, we drop school districts that within a certain distance to the nearest wildfire perimeter in that year. The estimated effects remain fairly stable even when dropping districts that are within 6.2 miles (10 kilometers) to the nearest fire perimeter. 95\% confidence intervals are shown with standard errors clustered by county. 


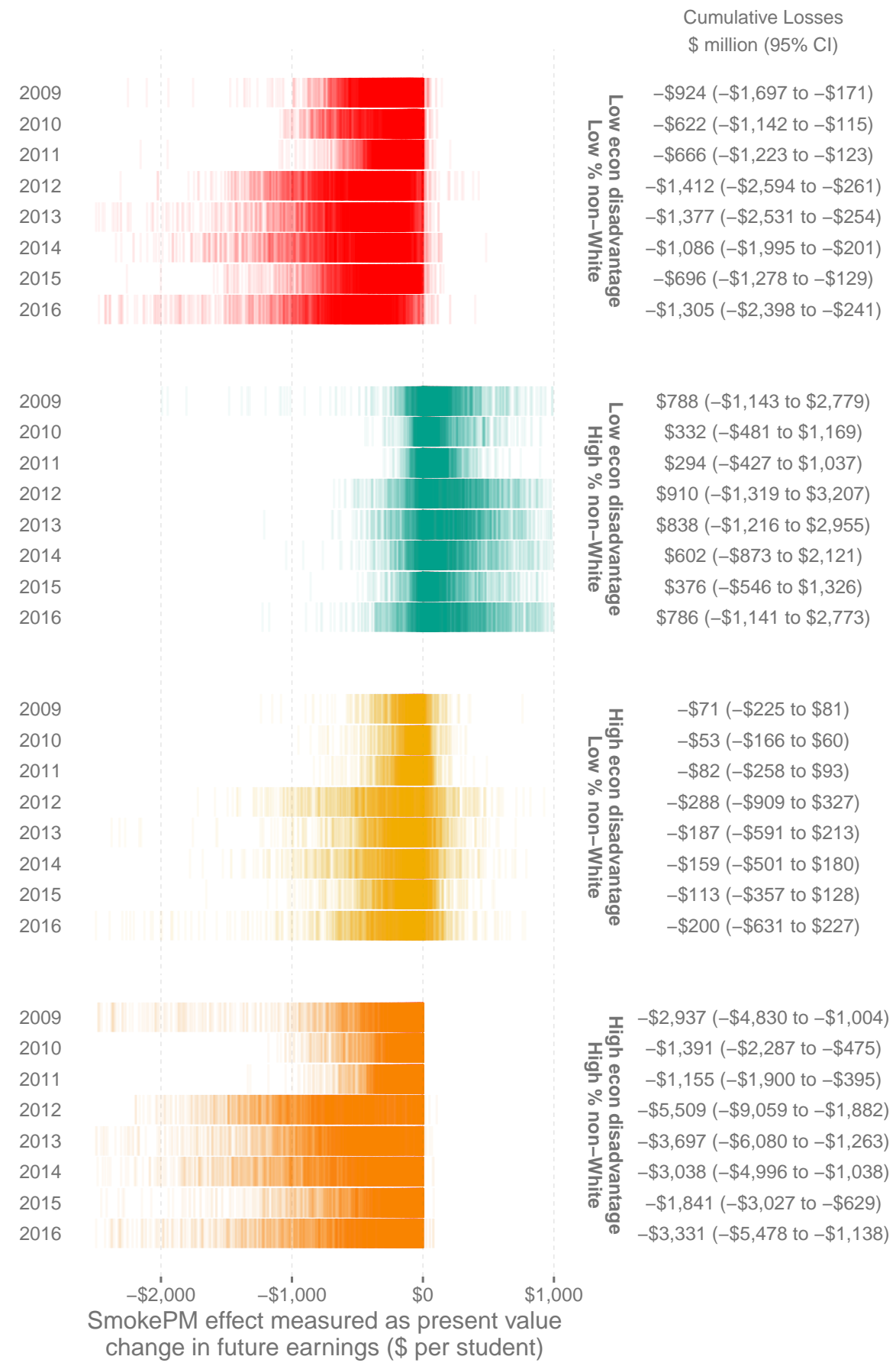

Fig. S4. Effect of total cumulative smoke $\mathrm{PM}_{2.5}$ on the net present value of future earnings separated by year, economic disadvantage, and racial-ethnic subgroup. Figure differs from the Figure $4 \mathrm{~B}$ in the main text as it uses estimates identified using total (school and non-school) day smoke $\mathrm{PM}_{2.5}$ exposure rather than just school day smoke $\mathrm{PM}_{2.5}$. 
Table S1. Median cumulative smoke $\mathbf{P M}_{2.5}$ exposure by race/ethnicity on school and non-school days

\begin{tabular}{|c|c|c|c|c|c|c|c|c|c|c|}
\hline \multirow[b]{2}{*}{ Category } & \multicolumn{2}{|c|}{ Asian } & \multicolumn{2}{|c|}{ Black } & \multicolumn{2}{|c|}{ Hispanic } & \multicolumn{2}{|c|}{ Native Amer. } & \multicolumn{2}{|c|}{ White } \\
\hline & High & Low & High & Low & High & Low & High & Low & High & Low \\
\hline Nonschool SmokePM & 48.49 & 50.86 & 45.38 & 54.61 & 45.70 & 52.60 & 49.15 & 49.81 & 58.00 & 39.58 \\
\hline School SmokePM & 19.96 & 20.16 & 18.26 & 22.20 & 19.79 & 20.28 & 19.97 & 20.13 & 23.11 & 16.80 \\
\hline
\end{tabular}

Notes: Exposure to wildfire smoke $\mathrm{PM}_{2.5}$ is noticeably greater on non-school days as this includes the summer period before school begins. 
Table S2. Median cumulative smoke $\mathrm{PM}_{2.5}$ exposure by economic disadvantage on school and non-school days

\begin{tabular}{lcr}
\hline & \multicolumn{2}{c}{ \% Economic Disadvantage } \\
\cline { 2 - 3 } Category & High & Low \\
\hline Nonschool SmokePM & 42.08 & 55.63 \\
School SmokePM & 17.41 & 22.45 \\
\hline
\end{tabular}


Table S3. \% of districts by subgroup within each average baseline $\mathbf{P M}_{2.5}$ bin.

\begin{tabular}{llll}
\hline & \multicolumn{3}{c}{ Avg. baseline $\mathrm{PM}_{2.5}$} \\
\cline { 2 - 4 } Econ disadvantage \& racial-ethnic subgroup & Low & Medium & High \\
\hline High econ dis \& High \% non-White & 37.60 & 33.02 & 29.38 \\
High econ dis \& Low \% non-White & 47.47 & 27.83 & 24.70 \\
Low econ dis \& High \% non-White & 37.61 & 32.12 & 30.27 \\
Low econ dis \& Low \% non-White & 43.95 & 28.70 & 27.35 \\
\hline
\end{tabular}

Notes: A district's baseline $\mathrm{PM}_{2.5}$ is calculated as the average yearly $\mathrm{PM}_{2.5}$ across the sample and bins are created by splitting the data into terciles. 
Table S4. Lagged impacts of school day smoke $\mathrm{PM}_{2.5}$ exposure

\begin{tabular}{lccc}
\hline Model: & $(1)$ & $(2)$ & $(3)$ \\
\hline Variables & & & \\
Contemporaneous year school smoke $\mathrm{PM}_{2.5}$ & -0.004 & -0.007 & -0.010 \\
& $(0.002)$ & $(0.003)$ & $(0.003)$ \\
1 year lagged school smoke PM 2.5 & & -0.004 & -0.005 \\
& & $(0.003)$ & $(0.003)$ \\
2 year lagged school smoke PM 2.5 & & & -0.007 \\
& & & $(0.003)$ \\
\hline Fixed-effects & & & \\
District & $\checkmark$ & $\checkmark$ & $\checkmark$ \\
Year x Grade & $\checkmark$ & $\checkmark$ & $\checkmark$ \\
\hline Controls & & & \\
Temperature & $\checkmark$ & $\checkmark$ & $\checkmark$ \\
Precipitation & $\checkmark$ & $\checkmark$ & $\checkmark$ \\
\hline Observations & & & \\
\end{tabular}

Notes: Standard errors clustered by county are shown in parentheses. Effect estimates are represented as a percent of a standard deviation change in average test score. 